\title{
Dear Author
}

Here are the proofs of your article.

- You can submit your corrections online, via e-mail or by fax.

- For online submission please insert your corrections in the online correction form. Always indicate the line number to which the correction refers.

- You can also insert your corrections in the proof PDF and email the annotated PDF.

- For fax submission, please ensure that your corrections are clearly legible. Use a fine black pen and write the correction in the margin, not too close to the edge of the page.

- Remember to note the journal title, article number, and your name when sending your response via e-mail or fax.

- Check the metadata sheet to make sure that the header information, especially author names and the corresponding affiliations are correctly shown.

- Check the questions that may have arisen during copy editing and insert your answers/corrections.

- Check that the text is complete and that all figures, tables and their legends are included. Also check the accuracy of special characters, equations, and electronic supplementary material if applicable. If necessary refer to the Edited manuscript.

- The publication of inaccurate data such as dosages and units can have serious consequences. Please take particular care that all such details are correct.

- Please do not make changes that involve only matters of style. We have generally introduced forms that follow the journal's style.

- Substantial changes in content, e.g., new results, corrected values, title and authorship are not allowed without the approval of the responsible editor. In such a case, please contact the Editorial Office and return his/her consent together with the proof.

- If we do not receive your corrections within 48 hours, we will send you a reminder.

- Your article will be published Online First approximately one week after receipt of your corrected proofs. This is the official first publication citable with the DOI. Further changes are, therefore, not possible.

- The printed version will follow in a forthcoming issue.

\section{Please note}

After online publication, subscribers (personal/institutional) to this journal will have access to the complete article via the DOI using the URL:

http://dx.doi.org/10.1007/s12024-018-0054-z

If you would like to know when your article has been published online, take advantage of our free alert service. For registration and further information, go to:

http://www.link.springer.com.

Due to the electronic nature of the procedure, the manuscript and the original figures will only be returned to you on special request. When you return your corrections, please inform us, if you would like to have these documents returned. 


\section{Metadata of the article that will be visualized in OnlineFirst}

Article Title Violence in the Early Bronze Age. Diagnosis on skull lesions using anthropological, taphonomic and scanning electron microscopy techniques

Article Sub-

Title

Article Springer Science+Business Media, LLC, part of Springer Nature 2018

Copyright Year (This will be the copyright line in the final PDF)

Journal Name Forensic Science, Medicine and Pathology

Family Name Pasini

Particle

Given Name Alba

Author

Suffix

Division Department of Biomedical Sciences and Surgical

Specialties, Faculty of Medicine, Pharmacy and Prevention

Organization University of Ferrara

Address Corso Ercole I d'Este 32, 44121 Ferrara, Italy

Family Name Gualdi-Russo

Particle

Given Name Emanuela

Suffix

Corresponding Division Department of Biomedical Sciences and Surgical

Author Specialties, Faculty of Medicine, Pharmacy and Prevention

Organization University of Ferrara

Address

e-mail

Corso Ercole I d'Este 32, 44121 Ferrara, Italy

emanuela.gualdi@unife.it

\begin{tabular}{lll}
\hline & $\begin{array}{l}\text { Family Name } \\
\text { Particle } \\
\text { Given Name } \\
\text { Author }\end{array}$ & Scianò \\
& $\begin{array}{l}\text { Fuffix } \\
\text { Division }\end{array}$ & $\begin{array}{l}\text { Department of Biomedical Sciences and Surgical } \\
\text { Specialties, Faculty of Medicine, Pharmacy and Prevention }\end{array}$ \\
& $\begin{array}{l}\text { Organization } \\
\text { Address }\end{array}$ & $\begin{array}{l}\text { University of Ferrara } \\
\text { Corso Ercole I d'Este 32, 44121 Ferrara, Italy }\end{array}$ \\
\hline \multirow{3}{*}{ Author } & Family Name & Thun Hohenstein \\
& $\begin{array}{l}\text { Particle } \\
\text { Given Name }\end{array}$ & Ursula \\
& Suffix & \\
& Division & Department of Humanities \\
& Organization & University of Ferrara
\end{tabular}




\section{AUTHOR'S PROOF}

\begin{tabular}{ll}
\hline & Address $\quad$ Ferrara, Italy \\
Schedule & $\begin{array}{l}\text { Received } \\
\text { Revised } \\
\text { Accepted }\end{array}$ \\
\hline Abstract & $\begin{array}{l}\text { In this paper we present the study of a skull belonging to a young male from the } \\
\text { Italian Bronze Age showing three perimortem injuries on the frontal and } \\
\text { parietal bones; the peculiarity of the frontal injury is represented by its singular } \\
\text { shape, which may be indicative of the weapon that caused the lesion. The aim } \\
\text { of the present study is to examine the traumatic evidence in relation to possible } \\
\text { etiological factors, in order to attempt to establish if the lesion occurred peri or } \\
\text { post-mortem, and to evaluate if these traumatic injuries could be interpreted as } \\
\text { an evidence of interpersonal violence, by combining anthropological, } \\
\text { taphonomic and ESEM investigations. The combination of multidisciplinary } \\
\text { methods of study can provide important new insights into inter-personal } \\
\text { violence. }\end{array}$ \\
\hline $\begin{array}{l}\text { Keywords } \\
\text { (separated by }\end{array}$ & $\begin{array}{l}\text { Skeletal remains - Cranial injury - Interpersonal violence - Taphonomic } \\
\text { '-') }\end{array}$ \\
\hline $\begin{array}{l}\text { Foot note } \\
\text { information }\end{array}$ & \\
\hline
\end{tabular}


4

\title{
Violence in the Early Bronze Age. Diagnosis on skull lesions using anthropological, taphonomic and scanning electron microscopy techniques
}

\author{
Alba Pasini $^{1}$ • Emanuela Gualdi-Russo ${ }^{1}$ • Filippo Scianò ${ }^{1}$ • Ursula Thun Hohenstein ${ }^{2}$ \\ Accepted: 5 November 2018 \\ (C) Springer Science+Business Media, LLC, part of Springer Nature 2018
}

\begin{abstract}
In this paper we present the study of a skull belonging to a young male from the Italian Bronze Age showing three perimortem injuries on the frontal and parietal bones; the peculiarity of the frontal injury is represented by its singular shape, which may be indicative of the weapon that caused the lesion. The aim of the present study is to examine the traumatic evidence in relation to possible etiological factors, in order to attempt to establish if the lesion occurred peri or post-mortem, and to evaluate if these traumatic injuries could be interpreted as an evidence of interpersonal violence, by combining anthropological, taphonomic and ESEM investigations. The combination of multidisciplinary methods of study can provide important new insights into inter-personal violence.
\end{abstract}

Keywords Skeletal remains $\cdot$ Cranial injury $\cdot$ Interpersonal violence $\cdot$ Taphonomic analysis $\cdot$ Forensic anthropology

\section{Introduction}

The collection of the Department of Biomedical Sciences and Surgical Specialties at University of Ferrara includes human skeletal remains of prehistoric and historical epochs.

In the present study, we examined the case of a skull with a frontal injury from the Italian Early Bronze Age (EBA). Since the interpretation of trauma is an essential task for forensic anthropologists, the primary focus of our study is to establish the possible cause of death of the individual and to evaluate if the traumatic injury could be interpreted as an evidence of interpersonal violence.

Emanuela Gualdi-Russo emanuela.gualdi@unife.it

1 Department of Biomedical Sciences and Surgical Specialties, Faculty of Medicine, Pharmacy and Prevention, University of Ferrara, Corso Ercole I d'Este 32, 44121 Ferrara, Italy

2 Department of Humanities, University of Ferrara, Ferrara, Italy

\section{Materials and methods}

Among the commingled remains of 27 individuals from Ballabio (Lecco, Italy) [1, 2], a skull (devoid of a mandible) presenting a peculiar injury on the frontal bone was found (Fig. 1).

The skull was analyzed by traditional anthropological methods to determine the sex of the decedent [3-5] and to estimate their age at death [3, 4, 6-9]. Osteometric traits of the skull were measured directly, when possible.

Description and interpretation of traumas were performed according to documented methods commonly applied in forensic anthropology to assess their nature (peri or post-mortem, accidental or intentional) [10-16].

Taphonomic analysis included macroscopic and microscopic observations through Environmental Scanning Electronic Microscope (ESEM). Replicas of the marks $[17,18]$ were made to perform ESEM analyses on small areas of the surfaces to evaluate possible traumatic marks, avoiding metallization of the original specimen and assuring a high degree of definition/reproduction of traces below $1 \mu \mathrm{m}[19,20]$. Silicone elastomer for casts and epoxy resin were used for positive copies. 
Fig. 1 Male skull from Ballabio: (a) frontal view; (b) lateral view (circles show location of the parietal injuries, arrow indicates the radiating fracture); (c) superior view
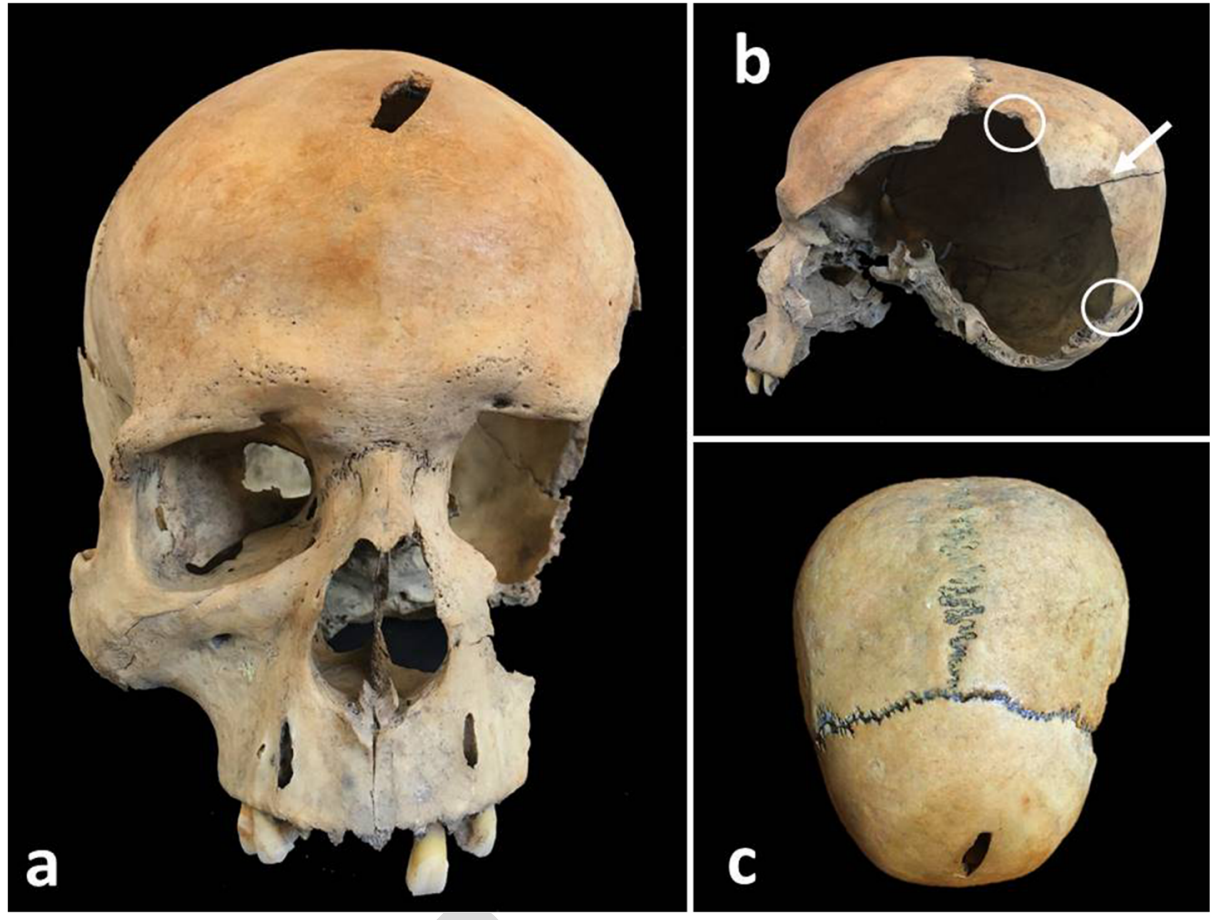

Craniofacial restoration, reconstruction and modelling were performed by computer graphics according to methodological indications [21-25]. A 3-D model of the skull was generated by NextEngine Desktop Scanner. A mandible from the same necropolis and consistent with the biological profile of the individual was scanned and adapted to the skull for reconstruction purposes. A generic head model (FaceGen) was imported and molded on the skull tagged with markers oriented orthogonal to cranial surfaces.

\section{Results}

The skull was found to be in a good state of preservation. According to our assessment, the subject was a young adult male (25-35 years old), brachycranial, with a middle upper

Table 1 Measurements and indices of the Ballabio skull (measures collected on the virtual skull are in italics)

.

.

\begin{tabular}{ll} 
Traits & \\
\hline -Maximum cranial length $(\mathrm{mm})$ & 181 \\
-Maximum cranial breadth $(\mathrm{mm})$ & 147 \\
Cranial Index & 81.2 \\
-Upper facial height $(\mathrm{mm})$ & 67 \\
-Bizygomatic breadth $(\mathrm{mm})$ & 133 \\
Upper facial index & 50.4 \\
-Nasal height (mm) & 50 \\
-Nasal breadth (mm) & 25 \\
Nasal index & 50 \\
\hline
\end{tabular}

face and mesorhinous (Table 1). No pathological evidences were observed.

Virtual restoration of the missing portions of the skull was carried out digitally before reconstruction, and a standard head of a male Caucasoid of the same age was molded on the soft tissue thickness indicators (Fig. 2). Some characteristics of the face (lip thickness, pigmentation, hairiness) were freely chosen from those possible in Caucasoid persons.

A sub-rectangular penetrating injury measuring $2.7 \times 0.9 \mathrm{~cm}$ was observed on the frontal bone (Fig. 3a). The right edge of the injury presented a sub-circular widening, while the other

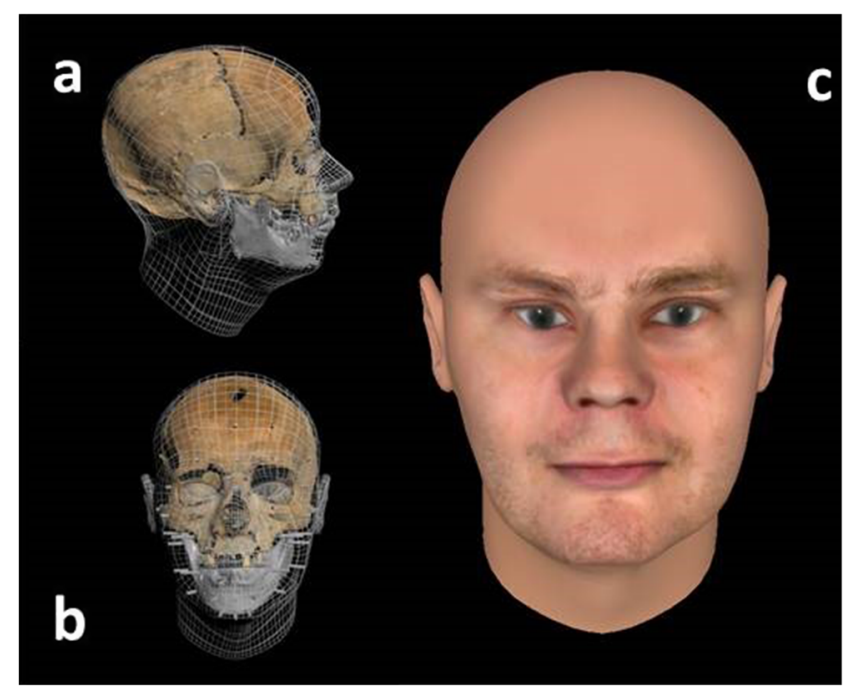

Fig. 2 Left pictures show profile (a) and frontal (b) views of the textured skull after adaptation of a generic head. The right picture (c) represents the final facial reconstruction of the man from Ballabio 
Fig. 3 Injuries on the frontal bone (a), parietal bone $(\mathbf{b}, \mathbf{c})$ and radiating fracture on the parietal bone (d)
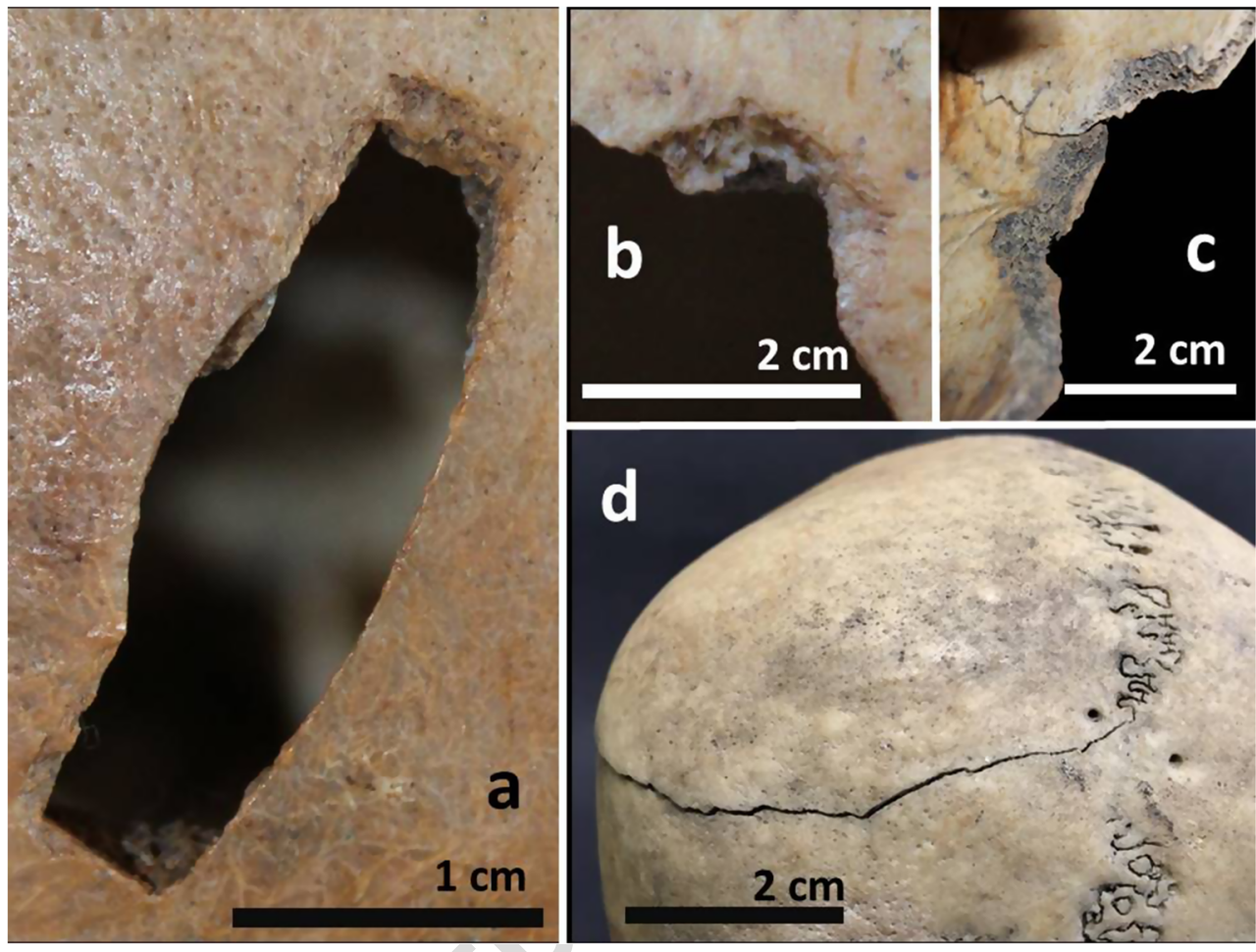

margins appeared regularly straight and sharp. The inner wall of the right margin is slanting to the cranial vault, while the left one is perpendicular to the cranial vault. Micro-fractures on the inner and outer surface were observed. The endocranial surface showed marked bevelling and partial exposition of the diploe. No radiating or additional fractures were observed for this injury. The absence of healing processes pointed to this trauma as occurring peri-mortem [10-16, 26, 27].

The presence of a traumatic breakthrough, attested by the stepped morphology of the edges and the presence of microfracturing, was observed by ESEM (Fig. 4). The impact point was located on the left side, given the presence of a sharper edge and a sub-circular operculum.

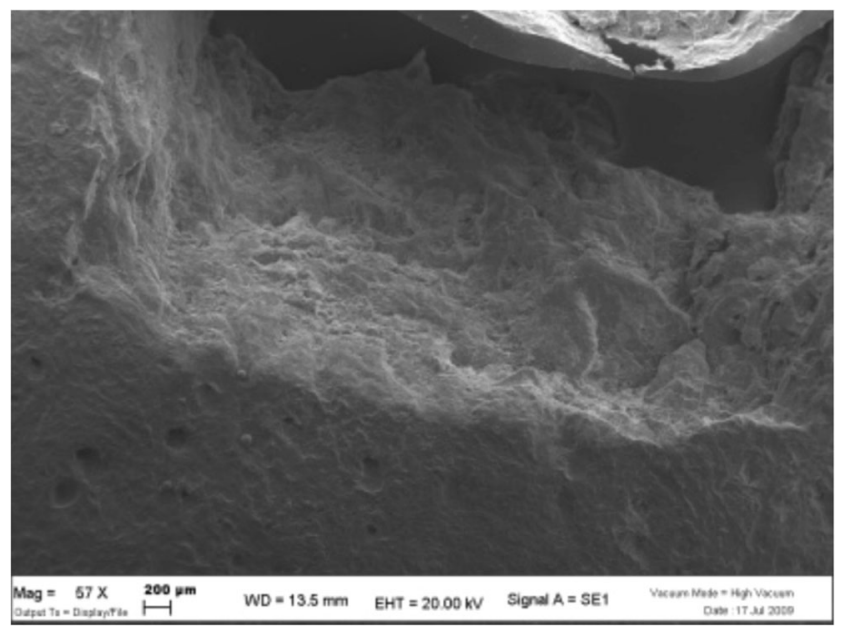

Fig. 4 Picture from the ESEM analysis of the frontal injury
Two further wounds were observed on the left parietal bone, presenting features similar to the frontal injury (regular margins, bevelling of the endocranial diploe) (Fig. 3b-c), along with a clearly distinguishable fracture, crossing the parietal bone to the coronal suture (Fig. 3d).

\section{Discussion}

The biological profile of this case suggests the man died at a young age and there is evidence of him suffering a violent death. His relatively large skull and the intermediate values of the facial and nasal indices are consistent with the characteristics of the Alpine populations.

The primary focus of our analysis was to assess whether the lesions were inflicted intentionally or accidentally. As pointed out by several researchers [28-31], injuries located on cranial bones are usually related to violence, indicating the action was intentional. The presence of multiple traumas provides further confirmation of an interpersonal violence case [15].

The singularity of the frontal trauma led us to assess the typology of the weapon involved in the traumatic evidence. Features of the Ballabio skull injuries are not consistent with a sharp force trauma provided by dirks, since their typical marks (a narrow V-shaped groove with a distinct apex at the bottom or a broader U-shaped groove with a flat bottom) $[10,15,32$, 33] were not observed in the present case.

Chopping or slashing wounds can be caused both by sharp and blunt forces (axes or heavy swords) [13, 15, 32]; evidence 
of this weapon type being used are similar to sharp-force injury marks; a fractured appearance of the injury edges and impression fractures, often with loose fragments [15].

Light and short swords such as were usually used in the EBA generate slashing traumas with incision marks including Vshaped kerfs, a narrow cross-section and minimal wastage [34].

Typical EBA axes were excluded as being the weapon used in this case since they create damage through a combination of incision and percussion [32, 34]; despite their small dimensions, these axe types can cause typical hacking wounds, characterized by significant wastage, breakage and fracturing, with concentric and depressed fractures characterizing cranial injuries [15, 34]; moreover, this weapon class does not create square-shaped or cleft-shaped defects [15, 34].

Typical projectile injuries present penetrating or grazing defects with complete, linear, radiating, and multifragmented fractures; the lesion shape is usually influenced by the shape of the projectile itself $[2,3,10,15,33]$. When there is a combined action of pointed and sharp forces (i.e. penetrating tools with one or more sharp edges, such as metallic arrowheads), a mold fenestration with at least one sharp edge, due to the divaricating action of the blade, is present [13].

Considering the morphology of the lesion in this case we hypothesize that they were inflicted by a perforating weapon or weapon-like object with a sharp edge, leaving typical geometrical and square shaped lesions of the same size as the tool involved [35]. Moreover, the presence of a sub-circular edge on the left margin of the frontal lesion led us to assume that extraction of the weapon caused the detachment of an operculum due to the application of a leverage action [13].

Although ESEM did not provide sufficient diagnostic elements on the composition (stone, metal, antler or bone) of the weapon, stone tools were excluded due to the absence of typical multiple striae and micro-fragments [36-38].

The two partially-conserved parietal wounds present features similar to the frontal lesion showing endocranial bevelling and a clear external margin. The fracture crossing the parietal bone shows typical traits of radiating fractures, such as elastic deformation, sharp edges, and theabsence of discoloration [27, 39]; this traumatic evidence was generated by a high-energy impact propagating from the impact site along path of least resistance up to the coronal suture [27, 39].

We assessed that all fractures were caused by the same weapon class. The absence of healing processes led us to conclude that all of the injuries were inflicted peri-mortem, probably during the same traumatic event. We cannot determine the exact sequence of the different impacts, although this individual was probably attacked first from his upper-left side, as shown by the frontal wound, and then laterally.

In conclusion, since bone lesions are frequently found in homicide victims [40], the reported case could be of interest in the forensic context when potential signs of violence are detected on skeletal remains. Depending on the degree of skeletonization, anthropological and taphonomic analyses may be usefully applied to investigate and interpret injuries on skeletal remains.

Acknowledgments The authors acknowledge Rita Bovolenta, Valentina Russo and Simonetta Zonari for technical support. Thanks also to Vanessa Manzon and Letizia Fazzari for collaboration in preliminary studies.

\section{Compliance with ethical standards}

Ethical approval Not required.

Conflict of interest The authors declare that they have no conflicts of interest.

\section{References}

1. Masotti S, Varalli A, Goude G, Moggi-Cecchi J, Gualdi-Russo E. A combined analysis of dietary habits in the Bronze Age site of Ballabio (northern Italy). Archaeol Anthropol Sci. 2017:1-19.

2. Manzon VS, Thun Hohenstein U, Gualdi-Russo E. Injuries on a skull from the Ancient Bronze Age (Ballabio, Lecco, Italy): a natural or an anthropic origin? J Archaeol Sci. 2012;39:3428-35.

3. Ferembach D, Schwydeski I, Stloukal M. Recommendations for age and sex diagnoses of skeletons. J Hum Evol. 1980.

4. Buikstra JE, Ubelaker DH. Standards for data collection from human skeletal remains. Fayetteville: Arkansas Archaeological Survey Research Sereries No. 44. 1994.

5. Krogman WM, Iscan MY. The human skeleton in forensic medicine. Springfiled: Charles C Thomas Publisher; 1986.

6. Lovejoy CO. Dental wear in the Libben population: its functional pattern and role in the determination of adult skeletal age at death. Am J Phys Anthropol. 1985;68:47-56.

7. Ubelaker DH. Human skeletal remains: excavation, analysis, interpretation. 2nd ed. Washington DC: Taraxacum; 1989.

8. Brooks S, Suchey JM. Skeletal age determination based on the os pubis: a comparison of the Acsádi-Nemeskéri and Suchey-brooks methods. Hum Evol. 1990;5:227-38.

9. Acsádi G, Nemeskéri J. History of human life span and mortality. Budapest: Akadémiai Kiadó; 1970.

10. Sauer NJ. Manner of death: skeletal evidence of blunt and sharp instrument wounds. In: Rathbun TA, Buikstra JE, editors. Human identification: case studies in forensic anthropology. Springfield: Charles C Thomas Publisher; 1984. p. 177-84.

11. Lovell NC. Trauma analysis in paleopathology. Yrbk Phys Anthr. 1997;40:139-70.

12. Sauer NJ. The timing of injuries and manner of death: distinguishing among antemortem, perimortem and postmortem trauma. In: Reichs KJ, editor. Forensic osteology: advances in the identification of human remains. Springfield: Charles C Thomas Publisher; 1998. p. 321-32.

13. Cattaneo C, Grandi M. Antropologia e odontologia forense. Guida allo studio dei resti ossei. Milano: Monduzzi; 2004.

14. Moraitis K, Spiliopuolou C. Identification and differential diagnosis of perimortem blunt force trauma in tubular long bones. Forensic Sci Med Pathol. 2006;2:221-9.

15. Kimmerle EH, Baraybar JP. Skeletal trauma: identification of injuries resulting from human rights abuse and armed conflict. Boca Raton: CRC Press; 2008.
188

189

190

191

192

193

194

195

196

197

198

199

200

201

202

203

204 
16. Pickering RB, Bachmann D. The use of forensic anthropology. 2nd ed. Boca Raton: CRC Press; 2009.

17. Orschiedt J, Häuber A, Haidle MN, Alt KW, Buitrago-Téllez CH. Survival of a multiple skull trauma: the case of an early Neolithic individual from the LBK enclosure at Herxheim (Southwest Germany). Int J Osteoarchaeol. 2003;13:375-83.

18. Rose JJ. A replication technique for scanning electron microscopy: applications for anthropologists. Am J Phys Anthropol. 1983;62:255-61.

19. Shipman P. Lifehistory of a fossil: an introduction to taphonomy and palaeoecology. Cambridge: Harvard University Press; 1981.

20. D'Errico F. Lecture technologique de l'art mobilier gravé. Nouvelles méthodes et premiers résultats sur les galets gravés de Rochedane. Anthropologie. 1988;92:101-22.

21. Iscan MY, Helmer RP. Forensic analysis of the skull: craniofacial analysis, reconstruction, and identification. New York: Wiley; 1993.

22. Kähler K, Haber J, Seidel HP. Reanimating the dead: reconstruction of expressive faces from skull data. ACM TOG (SIGGRAPH Conf proceedings). 2003;22:554-61.

23. Wilkinson C. Forensic facial reconstruction. Cambridge: Cambridge University Press; 2004.

24. Gualdi-Russo E, Zaccagni L, Russo V. Giovanni Battista Morgagni: facial reconstruction by virtual anthropology. Forensic Sci Med Pathol. 2015;11:222-7.

25. Miranda GE, Wilkinson C, Roughley M, Beaini TL, Melani RFH. Assessment of accuracy and recognition of threedimensional computerized forensic craniofacial reconstruction. PLoS One. 2018;13:e0196770.

26. Barbian LT, Sledzik PS. Healing following cranial trauma. J Forensic Sci. 2008;53:263-8.

27. Iscan MY, Steyn M. The human skeleton in forensic medicine. 3rd ed. Springfield: Charles C Thomas Publisher; 2013.

28. Walker PL. Cranial injuries as evidence of violence in prehistoric southern California. Am J Phys Anthropol. 1989;80:313-23.

29. Jiménez-Brobeil SA, Du Souich P, Al Oumaoui I. Possible relationship of cranial traumatic injuries with violence in the South-East
Iberian Peninsula from the Neolithic to the Bronze Age. Am J Phys Anthropol. 2009;140:465-75.

30. Lieverse AR, Pratt IV, Schulting RJ, Cooper DML, Bazaliiskii VI, Weber AW. Point taken: an unusual case of incisor agenesis and mandibular trauma in Early Bronze Age Siberia. Int J Paleopathol. 2014;6:53-9.

31. Lefèvre T, Alvarez JC, Lorin de la Grandmaison G. Discriminating factors in fatal blunt trauma from low level falls and homicide. Forensic Sci Med Pathol. 2015;11:152-61.

32. Schmitt A. Forensic anthropology and medicine: complementary sciences from recovery to cause of death. 1st ed. Totowa: Humana Press; 2006.

33. Brickley M, Ferllini R. Forensic anthropology: case studies from Europe. Springfield: Charles C Thomas; 2007.

34. Downing M, Fibiger L. An experimental investigation of sharp force skeletal trauma with replica Bronze Age weapons. J Archaeol Sci Rep. 2017;11:546-54.

35. Lewis JE. Identifying sword marks on bone: criteria for distinguishing between cut marks made by different classes of bladed weapons. J Archaeol Sci. 2008;35:2001-8.

36. Greenfield HJ. The origins of metallurgy: distinguishing stone from metal cut-marks on bones from archaeological sites. J Archaeol Sci. 1999:26:797-808.

37. Smith MJ, Brickley MB, Leach SL. Experimental evidence for lithic projectile injuries: improving identification of an underrecognised phenomenon. J Archaeol Sci. 2007:34:540-53.

38. Bertolini M, Thun Hohenstein U. Bevel-ended tools on large ungulate ribs during the Bronze Age in northern Italy: preliminary result of functional and experimental analyses. Quat Int. 2017;427:253-67.

39. Smith MJ, James S, Pover T, Ball N, Barnetson V, Foster B, et al. Fantastic plastic? Experimental evaluation of polyurethane bone substitutes as proxies for human bone in trauma simulations. Legal Med. 2015;17:427-35.

40. Flieger A, Kölzer SC, Plenzig S, Heinbuch S, Kettner M, Ramsthaler F, et al. Bony injuries in homicide cases (19942014). A retrospective study. Int J Legal Med. 2016;130:1401-8. 


\section{AUTHOR QUERIES}

\section{AUTHOR PLEASE ANSWER ALL QUERIES.}

Q1. Please confirm if the author names are presented accurately and in the correct sequence (given names/initials, family name).

Q2. Figure 4 contains poor quality and small text inside the artwork. Please do not re-use the file that we have rejected or attempt to increase its resolution and re-save. It is originally poor, therefore, increasing the resolution will not solve the quality problem. We suggest that you provide us the original format. We prefer replacement figures containing vector/editable objects rather than embedded images. Preferred file formats are eps, ai, tiff and pdf. 